\title{
A influência da Compreensão da Perspicácia do Enfermeiro e seu manejo clínico na Unidade de Cuidado Paliativo
}

\author{
The influence of the Understanding of the Nurse's Insight and its clinical management in the Pallia- \\ tive Care Unit \\ La influencia de la comprensión de la perspicacia del enfermero y su manejo clínico en la Unidad de \\ Cuidado Paliativo

\section{Rayssa Revellem Assis da Silva ${ }^{*}$, Sebastião Jorge da Cunha Gonçalves²} \\ Como citar esse artigo. da Silva, \\ RRA; Gonçalves, SJC. A influência

\section{Resumo} da Compreensão da Perspicácia do Enfermeiro e seu manejo clínico na Unidade de Cuidado Paliativo. Revista Pró-UniverSUS. 2019 Jan./Jun.; 10 (1): 60-65.

A relevância do estudo e a importância da atuação do enfermeiro encontram-se, em suas variadas dimensões, tem no desempenho profissional. Implicações negativas geradas pela pouca visibilidade da enfermagem estão relacionadas a insatisfação e ausência de motivação no contexto de trabalho. A falta de visibilidade da profissão pela equipe de saúde e pelos pacientes pode comprometer a construção de vínculos, como também a efetivação do cuidado. Apesar de existir uma equipe multidisciplinar nos cuidados paliativos, o enfoque será na atuação do Enfermeiro na unidade de cuidados paliativos. Buscando, confrontar os seus deveres e direitos para a assistência aos pacientes, focando no paciente em fase terminal de câncer. Tendo como metodologia pesquisa de campo, qualitativa e quantitativa de caráter exploratório, sendo utilizado um questionário para realizar a pesquisa com os profissional enfermeiro plantonista e diarista do Hospital Cruz Vermelha Brasileira.

Palavras-chave: Enfermagem; Cuidado Paliativo; Finitude.

\begin{abstract}
The relevance of the study and the importance of the nurses' performance are, in their varied dimensions, in the professional performance. Negative implications generated by the low visibility of nursing are related to dissatisfaction and lack of motivation in the work context. The lack of visibility of the profession by the health team and patients can compromise the construction of bonds, as well as the effectiveness of care. Although there is a multidisciplinary team in palliative care, the focus will be on the role of the Nurse in the palliative care unit. Wanted, confront their duties and rights for patient care, focusing on the terminal patient of cancer. Having as a qualitative and quantitative field research methodology, it was used a questionnaire to perform the research with the professional nurse on call and day care at the Brazilian Red Cross Hospital.
\end{abstract}

Keywords: Nursing; Palliative Care; Finitude.

\section{Resumen}

La relevancia del estudio y la importancia de la actuación del enfermero se encuentran, en sus variadas dimensiones, tiene en el desempeño profesional. Las implicaciones negativas generadas por la poca visibilidad de la enfermería están relacionadas con la insatisfacción y ausencia de motivación en el contexto de trabajo. La falta de visibilidad de la profesión por el equipo de salud y por los pacientes puede comprometer la construcción de vínculos, así como la efectividad del cuidado. A pesar de existir un equipo multidisciplinario en los cuidados paliativos, el enfoque será en la actuación del Enfermero en la unidad de cuidados paliativos. Buscando, confrontar sus deberes y derechos para la asistencia a los pacientes, enfocándose en el paciente en fase terminal de cáncer. Con una metodología de investigación de campo, cualitativa y cuantitativa de carácter exploratorio, se utilizó un cuestionario para realizar la investigación con los profesionales enfermero plantonista y diarista del Hospital Cruz Roja Brasileña.

Palabras clave: Enfermería; Cuidado Paliativo; Finitud. 


\section{Introdução}

Comenta-se com frequência, a respeito da importância do Profissional de Enfermagem. Devido ao grande número de debate, que muitas vezes é realizado de forma insensata, algumas pessoas acabam desmerecendo esta profissão, que é de suma importância para qualquer Unidade de Saúde, tendo como foco os cuidados paliativos em pacientes oncológicos.

Apesar de existir uma equipe multidisciplinar nos cuidados paliativos, o enfoque será na atuação do Enfermeiro na unidade de cuidados paliativos. Buscado, confrontar os seus deveres e direitos para a assistência aos pacientes.

Considerando que o câncer acomete todas as faixas etárias, a sua maior suscetibilidade está relacionada, sobretudo, aos fatores extrínsecos, tais como: o ambiente, em particular a ocupação, dieta, estresse e hábitos de vida. Trata-se, assim de uma doença complexa, que pode ser de longa duração e que compromete significativamente a vida dos indivíduos nas dimensões biológica, social e afetiva, exigindo assistência especializada de diferentes profissionais ${ }^{1}$.

Diante de um processo patológico como o câncer, o envolvimento familiar é inevitável. A família é a principal instituição social em que o indivíduo inicia suas relações afetivas, cria vínculos e internaliza valores. Essa relação familiar apresenta-se de forma interligada como se fosse à extensão do outro, pois acredita-se que a experiência de uma doença grave traz modificações no modo de pensar, sentir e agir das pessoas ${ }^{1}$.

O cliente com câncer deve contar com uma ampla estrutura de apoio para enfrentar as diferentes etapas do processo, pois requerem intensos cuidados, exigindo da equipe de enfermagem conhecimento científicos e habilidades no tocante ao reconhecimento de sinais e/ ou sintomas subjetivos próprios destes clientes ${ }^{2}$.

Diante do câncer, o paciente oncológico passa por uma mudança em suas relações sociais, familiares e consigo mesmo. Portanto, é necessário que haja uma assistência humanizada capaz de compreender e entender o sofrimento em todo processo da doença.

A assistência de enfermagem para pacientes com câncer, deve ser vista como cuidado pleno, encorajador, afetuoso e comprometido em auxiliar na adaptação às novas condições de vida. ${ }^{3}$

A percepção pelo enfermeiro dos problemas relacionadosmorbimortalidadeéfortementeinfluenciada por suas vivências, conhecimentos, valores éticos e pessoais, e nessa perspectiva cada indivíduo (paciente, profissional ou familiar) deve ser considerado como único, tendo necessidades, valores e crenças específicas, o impacto da doença e hospitalização do paciente e a influência da interação familiar sobre a causa e sua cura, tem obrigado a enfermagem a um compromisso de incluí-la nos cuidados de saúde. ${ }^{4}$

Sendo assim, é claramente visível a importância do profissional de enfermeiro, neste processo, considerando que esses profissionais estão na beira leito convivendo corriqueiramente com o cliente, conquistando a confiança do mesmo e de seus familiares, promovendo através de sua assistência um suporte psicossocial, conforto e higiene.

Acredita-se que com este estudo poderá contribuir e esclarecer que os cuidados prestados por estes profissionais, mostram que o acolhimento e manejo da equipe para com os clientes e seus acompanhantes, são essenciais evidenciando a importância da profissão nas unidades de cuidado paliativo.

Este trabalho tem como objetivo realizar uma pesquisa de campo sobre a importância da perspicácia do enfermeiro em uma unidade de cuidados paliativos, e obter a resposta da seguinte questão norteadora: Qual é perspicácia do enfermeiro e a importância do manejo clínico nos cuidados paliativos pela equipe de enfermagem em pacientes terminais.

A relevância do estudo e a importância da atuação do enfermeiro, encontram-se, em suas variadas dimensões, tem no desempenho profissional. Implicações negativas geradas pela pouca visibilidade da enfermagem estão relacionadas a insatisfação e ausência de motivação no contexto de trabalho. A falta de visibilidade da profissão pela equipe de saúde e pelos pacientes pode comprometer a construção de vínculos, como também a efetivação do cuidado.

\section{Materiais e Métodos}

Trata-se de uma pesquisa exploratória inicialmente com busca bibliográfica buscando familiaridade com o problema.

O método deste estudo é o quanti/quali. A pesquisa qualitativa não se preocupa com representatividade numérica, mas, sim, com o aprofundamento da compreensão de um grupo social, de uma organização, etc. Os pesquisadores que adotam a abordagem qualitativa opõem-se ao pressuposto que defende um modelo único de pesquisa para todas as ciências, já que as ciências sociais têm sua especificidade, o que pressupõe uma metodologia própria. Assim, os pesquisadores qualitativos recusam o modelo positivista aplicado ao estudo da vida social, uma vez que o pesquisador não pode fazer julgamentos nem permitir que seus preconceitos e crenças contaminem a pesquisa. .:34 $^{5}$

A pesquisa quantitativa, em geral tem características básicas, tais como: inferência dedutiva; a realidade investigativa é objetiva; a amostra é geralmente grande e determinada por critérios estatísticos; generalização dos resultados; utilização de dados que 
representam uma população específica; utilização de questionários estruturados com questões fechadas, testes e checkilist. O pesquisador deve formular hipótese, elucidando todos os fatores definidos. Com a coleta de dados poderá analisar cada hipótese e observar se os resultados são contraditórios ou não. ${ }^{6}$

O tipo de pesquisa foi de Campo. A pesquisa de campo é uma fase que é realizada após o estudo bibliográfico, para que o pesquisador tenha um bom conhecimento sobre o assunto, pois é nesta etapa que ele vai definir os objetivos da pesquisa, as hipóteses, definir qual é o meio de coleta de dados, tamanho da amostra e como os dados serão tabulados e analisados. As pesquisas de campo podem ser dos seguintes tipos. ${ }^{7}$

Cenário: Hospital Cruz Vermelha Brasileira - Filial Barra do Pírai/RJ. Referência em Cuidados Prolongados e em Idoso.

Foram participantes do estudo 8 Enfermeiros da Cruz Vermelha, Plantonistas e Diaristas. Para a seleção dos participantes, utilizou-se como critérios de inclusão, os enfermeiros do cenário descrito, que trabalham na da área urbana e que aceitassem participar, demonstrando aceite por meio da assinatura do Termo de Consentimento Livre e Esclarecido. Foram utilizados, como critérios de exclusão, enfermeiros que estavam em período de férias, licenças, ou que não localizados durante o período da coleta de dados. A unidade que integrou este estudo se deu de forma aleatória.

A coleta de dados foi realizada, no período de novembro de 2018, (na própria Instituição), em dias e horários escolhidos pelos próprios participantes, agendadas de acordo com sua disponibilidade. As entrevistas abordaram pontos tais como: de que modo o enfermeiro se percebe representado pelos pacientes e pela sociedade em geral, como essa representação interfere no seu dia a dia, fatores de (in)satisfação no trabalho e o que representa para ele ser enfermeiro, e sobre seus conhecimentos teórico-técnico, para que se obtivesse total fidedignidade aos relatos.

Após a coleta do questionário respondido, as dúvidas foram transcritas na integra, de forma atenta e minuciosa, sendo realizada uma leitura recorrente das mesmas para organização do material, em seguida de exploração exaustiva, para assim identificar as unidades estruturais significantes. Em seguida, os dados foram agrupados em categorias analíticas a partir dos sentidos e dos significados das falas dos sujeitos e analisadas a partir da análise de conteúdo.

Com a finalidade de preservar a identificação e garantir o sigilo, os participantes serão denominados por "PAR", seguidos do número correspondente a ordem em que foram entrevistados.

Todas as fases de realização da pesquisa contemplam a Resolução do CNS n. 466(6), e 510 de 12 de dezembro de 2012 e a mesma será aprovada pelo Comitê de Ética em Pesquisa da Universidade Vassouras (CEP/UV), sob o parecer $n^{\circ}$ 3.023.576. e CAAE: 97747118.1.0000.5290.

\section{Resultados e Discussão}

Seis eixos emergiram a partir dos objetivos propostos e questionário.

\section{A essência dos cuidados paliativos}

$\mathrm{O}$ cuidado paliativo ainda não é bem visto $\mathrm{e}$ reconhecido pela sociedade brasileira, vendo que os clientes em que necessitam desses cuidados já não se encontram em estado curativo e sim no estado de finitude, visando a dignidade, conforte e higiene, controlando os sintomas e não a doença. Muitos acham que quando uma pessoa necessita desse cuidado é porque não há mais nada para se fazer por aquele ser humano, porém Cicely Saunders (uma britânica que se graduou em enfermagem, assistência social e por último medicina), uma pioneira dos cuidados paliativos, fundadora do St. Christophor's Hospice em 1967, dizia que: “ainda há muito a se fazer".

Esse cuidado vai além de utilizar medicações para minimizar a dor, envolve também a ética e empatia pelo próximo, vendo que o papel do cuidador está devidamente danificado por suas emoções, então o apoio espiritual e psicológico também é de muita importância nesse momento para o âmbito familiar.

Existem 4 pilares que foram fundamentais para a criação dos cuidados paliativos, esses são conhecidos como: comunicação, controle sintomático, trabalho em equipe e apoio familiar.

Para que uma unidade especializada neste cuidado possa funcionar adequadamente é necessário atingirem esses pilares. Assim filosofia seja inserida adequadamente em uma unidade é necessário um conhecimento cientifico, teórico e técnico, e como está especialização é nova no Brasil muitas academias ainda não aderiram esse conteúdo nas grades acadêmicas, por isso o profissional em que compõe a equipe

\section{Gráfico 1.}

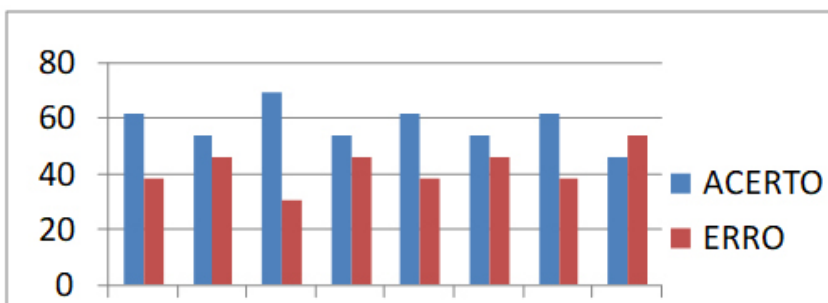

Par 1Par 2Par 3Par 4Par 5Par 6Par 7Par 8 
multiprofissional devem ser especializado.

Como se pode observar foram reunidas as questões que são quesitos básicos dos cuidados paliativos, os acertos estão a cima da média, porém os números de erros é muito considerável criando assim um déficit de conhecimento por conceitos básicos deste cuidado. Considerando que para a melhora destes profissionais de acordo com este gráfico, poderia haver uma capacitação sobre os assuntos abordados nas questões selecionadas. Visando que este cuidado ainda é novo para a sociedade e para academias de formação profissional, ainda não aderiram este conteúdo teórico, muitos profissionais acabam vendo e aprendendo somente na prática este tipo de cuidado.

\section{Morte, eutanásia e distanásia.}

É considerado morte quando o mecanismo do corpo já não consegue manter a homeostasia, podendo acontecer no início da vida, na vida adulta ou na velhice. Ninguém está preparado para o fator morte quando se trata de um ente querido, por isso os profissionais devem estar preparados para este momento, tentando compreender o sofrimento daquele cuidador, que muitas das vezes está mais fragilizado do que o doente. $\mathrm{O}$ enfermeiro é quem está à beira leito todos os dias em contato com os paciente/familiar, por esse motivo, o profissional responsável deve mostrar empatia, e sempre que solicitado, esclarecer dúvidas para não haver equívoco de gerar falsas esperanças, falar claramente sobre o quadro clínico em que se encontra.

Eutanásia é quando a vida humana é interrompida por algum profissional ou fator criminador, mais conhecido pelos advogados como ilícito penal ou também como suicídio assistido, existem várias formas de cometê-la. No Brasil eutanásia é considerada crime gravíssimo, o profissional pode até perder o poder de exercer sua função, sabe-se que quando um paciente em fase terminal é acometido por uma dor intensa o mesmo acaba indo ao delírio, por isso não deve ser levado em conta o que se pede, pois não é ele quem está falando e sim seu subconsciente. Tem países que hoje esta prática não é mais considerado um crime, são eles: Canadá, Bélgica, Holanda e Suíça. É de suma importância esclarecer que nos cuidados paliativos este ato não é aceitável, porque muitas das vezes os familiares não entendem ou não querem aceitar a morte, uma das primeiras fases do luto.

Distanásia, também conhecida como obstinação terapêutica é quando se prolonga a morte de uma pessoa, tendo assim uma morte lenta, aumentando o sofrimento, tanto dos familiares quanto dos pacientes, levando uma vida sem qualidade. Isso acontece quando o tratamento prestado não é de necessidade naquele momento, para aquele cliente, atos do curativismo em sua situação de finitude. Não só no Brasil, mas como em quase todo o mundo está prática ainda acontece extraordinariamente, talvez por falta de conhecimento ou compreensão familiar. Cabe os profissionais habilitados esclarecer suas tomadas de decisões perante a família, para que eles possam compreender a qualidade de vida para o cliente é o que nos importa nessa fase difícil.

O resultado mostra que o profissional enfermeiro entende sobre os assuntos mais indagados do cuidado

Gráfico 2.

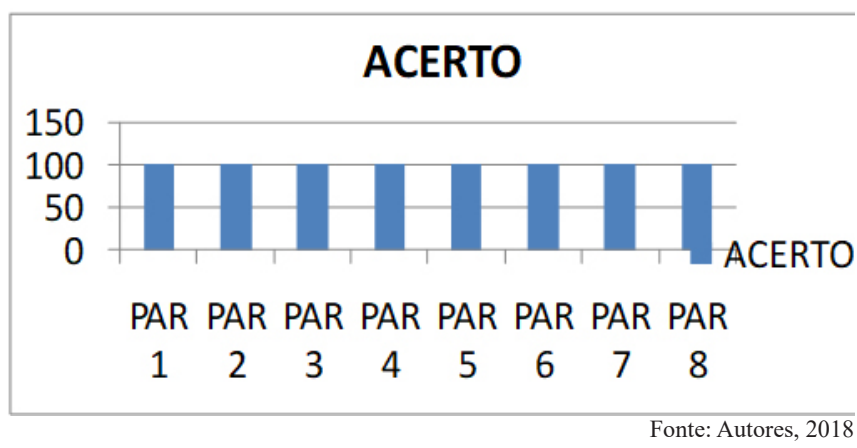

paliativo. Assim podendo e tendo sabedoria e perspicácia sobre o assunto.

\section{Doenças ameaçadoras de vida}

De acordo com este gráfico, eles também têm

Gráfico 3.

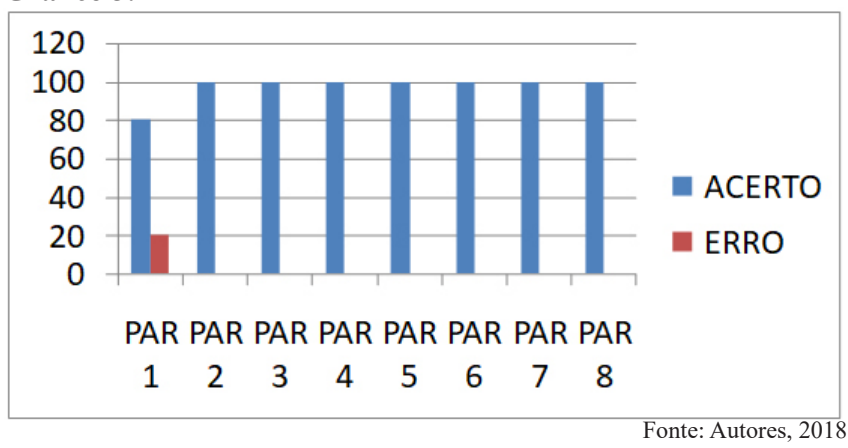

muito conhecimento sobre as doenças que acometem a vida, e lava a pessoa a necessitar deste cuidado tão especifico, pode se observar que uma pessoa teve $20 \%$ de erros, porém este pessoa pode ser consideravelmente leiga neste assunto ou um profissional de boa qualidade para auxiliara.

Saberes do Enfermeiro:

A atuação desse profissional compreende tarefas e relações que vão desde a interação com cada cliente até articulações mais complexas, com familiares, equipe de saúde multiprofissional e institucional, e permeia diferentes faces do processo de cuidado, desde a entrada até a saída do paciente, seja pela alta hospitalar, seja pelo óbito. ${ }^{8}$ O papel do enfermeiro assistencial é cuidar e 
supervisionar a equipe que prestará os cuidados, e com isso consequentemente ajudar para um tratamento de qualidade para os pacientes, porém, também é de seu dever zelar para que o número de erros cometidos pela equipe seja o menor possível.

Então é de sua competência saber sobre os medicamentos usados naquele setor, seus efeitos adversos, suas vias de administração e como administrar.

Começando a falar dos opioides é um psicoativo, achem sobre os receptores opioides atuando assim no sistema nervoso para obter o alivio da dor, são eles: Morfina e Tramadol, os mais usados.

Analgésicos, trabalham para diminuir ou aliviar a dor, atuando nas transmissões nervosas, o mais usado é: Dipirona. Chega um momento que a dor é tão grande que este medicamento já não faz tanto o efeito desejado.

Anticolinérgicos tem a ação principal de inibir a acetilcolina, o mais usado é Hioscina. Usados em cólicas no abdominal ou no estomacal e nos espasmos biliares.

Ante eméticos, medicações que tem o principal efeito evitar enjoo e náuseas, os mais usados: Ondansetrona e Haloperidol (também usado para agitações e agressividades).

Benzodiazepínicos, psicotrópicos, agonistas que achem sobre os receptores gabaminérgico, o mais usado: Diazepam, tem o efeito de calmante, de curta duração.

Todos esses medicamentos podem ser feitos por via subcutânea, podem ser diluídos com SF $0,9 \%$ ou com água injetável por $100 \%$.

A uma diferença de uma terapia subcutânea e a hipodermóclise, a terapia subcutânea é quando só há administração dos medicamentos, assim podendo chamar este acesso de hipodermóclise. Hipodermóclise é quando há necessidade de uma hidratação de SF $0,9 \%$ por via $\mathrm{SC}$, sendo aconselhável para pacientes em fase terminal, com dores elevadas, e com nutrição oral prejudicada assim comprometendo as vias periféricas.

A via SC é uma via de lenta absorção, porém com ação mais prolongada, podendo fazer uso da hipodermóclise em sua própria residência, pois o risco de infecção é mínimo e de baixo custo, com o método é simples e eficaz. E os sítios para punção são: Infraclavicular, face externa do deltóide, abdome, anterolateral da coxa e interescapular como bisel sempre voltados para os linfonodos mais próximos, para melhor absorção.

Com este resultado pode- se observar que os conhecimento do enfermeiro mais voltado pela a administração de seus medicamentos são um sobre a via de administração ainda existe algumas dúvidas, podendo ser falta de estudo sobre o assunto, durante os meses são realizadas farias capacitação acerca do que se encontra geralmente nos cuidados paliativos, porém o saber sempre é preciso.

\section{Dor e outros sintomas}

Gráfico 4.

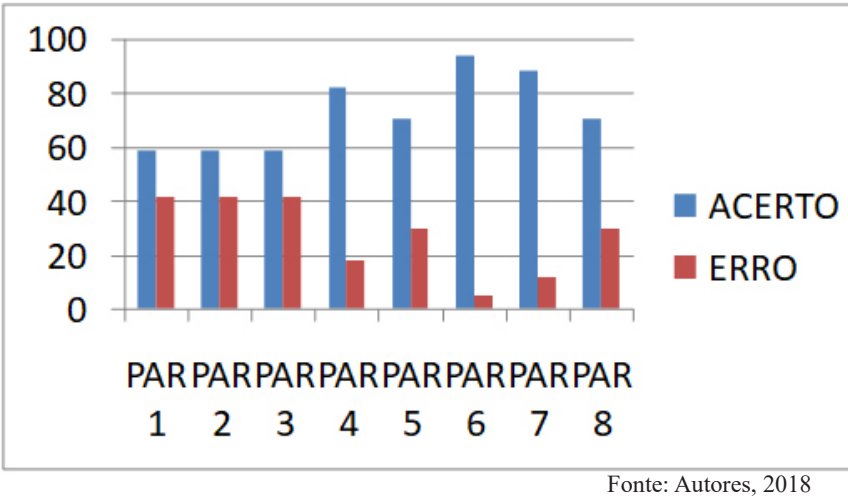

Existem dores: físicas, psicológicas, sociais e espirituais e nós como profissionais de ponta temos uma facilidade de distinguir. Se for uma dor física em sua fase terminal, temos que ter a conduta de lhe das as medicações em horários corretos, conforme a prescrição do médico, caso a dor aumentou solicitar uma nova avaliação da equipe. Para avaliar o nível da dor temos a Escala Visual Analógica (EVA) e focada para os cuidados paliativos a Escala de Edmonton que nos mostra todos os sinais e sintomas focados nos cuidados prestados, o Hospital em que a pesquisa foi realizada não utilizando dessa escala, tendo em vista que seria de muito aproveito para o enfermeiro. A escada analgésica da dor da OMS nos ensina como intervir nos graus da dor, que medicamento usar em cada grau, assim a unidade fica respaldada em qualquer iniciativa.

Quando a dor vai além da nossa capacidade, quando se trata de uma dor psicológica, social e espiritual, devemos nos mostrar empáticos, com o sobre do mesmo, dizer palavras de conforto ou até mesmo só ouvi-los, e quando necessário chamar os outros profissionais que integram da equipe multiprofissional, como o psicólogo, assistente social e o capelão.

Sintomas comuns em cuidados paliativos são: Náusea; Vômitos; Fadiga; Diarreia; Sudorese; Caquexia; Anorexia; Dispneia; Ansiedade; Depressão; Tosse; Brocorreia; Constipação; Delírio.

Sendo este eixouma dos gráficos mais importantes,

Gráfico 5.

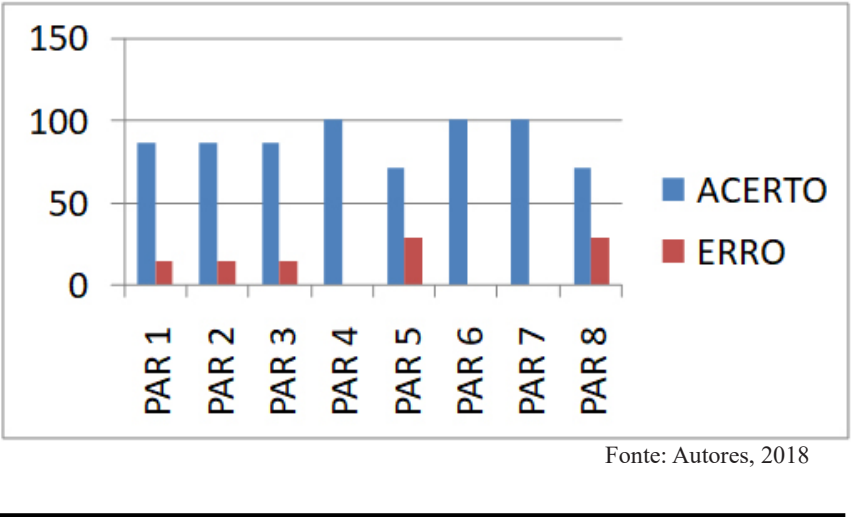


é de suma felicidade achar um valor tão reduzido de erros. Pois se entende que as maiorias dos profissionais entendem a dor do próximo, mesmo e levam a sério o seu trabalho de cuidar da pessoa em que se encontra muitas das vezes em dores não físicas. Acredita-se que poderia ser menor o número de erros, porém o resulto foi satisfatório.

\section{Comunicacão com o cuidador durante o processo da terminalidade e o apoio na fase do luto}

Falar do âmbito familiar é muito difícil, pois só os em que circulam o paciente sabe o real valor que o mesmo tem em sua vida, podendo ser ele o provedor do lar ou a adjuntora, um filho amado, o pai/mãe em que temos um laço desde bebê, então como olhar nos olhos destes e falar sobre fase terminal ou até mesmo a morte. A dor da perda é isolada e diferenciada em cada um, cada ser humano vai ter uma reação diferente perante o óbito.

Durante o processo de adoecimento, idas e vindas para a unidade de cuidado, vai gerando um medo e uma angustia, e cada vez mais dúvidas mediante os sintomas e quadro clínico, cabem a nós neste momento de fragilidade ter compreensão e saber se comunicar com o familiar. O mesmo pode se mostrar muito solícito ou acabar gerando mais demanda que o próprio paciente. Quando inserido o cuidado paliativo em um paciente terminal, devemos sempre lembrar que a mudança em que o cliente apresentar, seja ela física, psicológica, espiritual ou social, acaba refletindo no cuidador potencialmente, pois a partir de cada mudança que vai acontecer com o paciente, terá um efeito potencialmente significativo para os hábitos diários do cuidador.

Quando o óbito for declarado pelo médico em que compõe a equipe, vão começar o processo de acolhimento ao cuidador, o apoio psicológico e físico é fundamental para o momento do luto, demonstrar compaixão e compreensão para este momento lhe trará mais conforto.

O luto se consiste em 4 fases,,${ }^{9,10}$ : aceitar a realidade da perda; expressar a dor da perda; adaptar-se a um ambiente em que a pessoa está ausente; desligar-se emocionalmente da pessoa falecida e prosseguir com a vida.

Quando se trata de família, muitos profissionais se queixam da demanda em que a família traz para o setor, porém nos cuidados paliativos o familiar se encontra em um momento de despedida é devemos ter o mmáximo de empatia possível. Vendo este resultado acredito que algumas vezes podem deixar a emoção tocar conta de si e acabar se queixando ao algo do tipo, porém o número de acertos retrata que eles buscam ser mais humanos e apoiar os familiares em que se encontra passando pela fase de finitude, como cuidador.

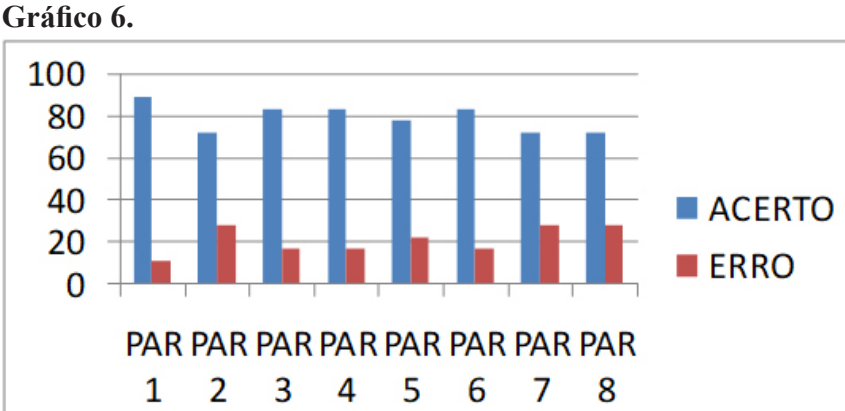

Fonte: Autores, 2018

\section{Conclusão}

Buscou-se com o estudo saber se os enfermeiros do Hospital Cruz Vermelha, filial da cidade de Barra do Piraí que visam os cuidados paliativos sabem reconhecer a sua perspicácia e seu manejo clínico naquele ambiente.

Verificamos que quando se trata da filosofia, pilares, conceito e história deste cuidado, ainda há muitas dúvidas, sabendo que é algo simultaneamente novo e a saúde é algo que muda constantemente, acredita-se que deveriam buscar saberes sobre este assunto para que assim possam obter um resultado mais fidedigno e com menor número de erros.

Conclui-se com este estudo que o hospital deveria prestar mais capacitações permanentes ou cursos para seus profissionais enfermeiros sobre a essência do cuidado paliativo, buscando assim um cuidado com mais qualidade e aprimoramento.

\section{Referências}

1. Souza MGG, Santo FHE. O olhar que olha o outro... um estudo com familiares de pessoas em quimioterapia antineoplásica. Revista Brasileira de Cancerologia, 2008;54(1):31 - 41 .

2. Souza AS, Valadares GV. Desvelando o saber/fazer sobre o diagnóstico de enfermagem: experiência vivida em neurocirurgia oncológica. Revista Brasileira de Enfermagem, 2011;64(5):890-7.

3. Casanova EG, Lopes GT. Comunicação da equipe de enfermagem com a família do paciente. Rev. Bras. de Cancerologia 2009;62(6):831-6.

4. Araújo HMA, Silva RM, Bonfim IM, Fernandes AFC. A comunicação da enfermeira na assistência de enfermagem à mulher mastectomizada: um estudo de Ground Theory. Rev. Latino am. Enferm. 2010;18(1):1-7.

5. Goldenberg M. A arte de pesquisar: como fazer pesquisa qualitativa em Ciências Sociais, $8^{\text {a }}$ edição. Rio de Janeiro: Record, 2004.

6. Dalfovo MS, Lana RA, Silveira A. Métodos quantitativos e qualitativos: um resgate teórico. Revista Interdisciplinar Científica Aplicada, Blumenau, 2008;2(4):01-13.

7. Lakatos EM, Marconi MA. Fundamentos de metodologia científica. São Paulo: 1996.

8. $\quad$ Firmino EAP. A inclusão digital de professores da Educação Básica Pública: o caso do Curso de Especialização em Gestão Escolar do Programa Nacional Escola de Gestores do Ministério da Educação. 2016.

9. Farias C. O processo de construção de cuidados enfermeiro/pessoa em sim de vida: encontro de corpos. 2011. 213 f. Dissertação (Mestrado) Universidade de Lisboa. Lisboa, 2011

10. Pacheco S. Cuidar a pessoa em fase terminal: perspectiva ética. 2.ed. Lourdes (Pt): Luso ciência, 2004

educativa. Escola Anna Nery, 2016;20(2):363-39. 